\title{
COMMENTARY
}

\section{The brain after critical illness: effect of illness and aging on cognitive function}

\author{
Ramona O Hopkins $s^{* 1,2}$ \\ See related research by Guerra et al., http://ccforum.com/content/16/6/R233
}

\begin{abstract}
Large numbers of patients who survive critical illness are left with significant new cognitive impairments that are often severe and remain years after hospital discharge. In the previous issue of Critical Care, Guerra and colleagues assessed risk factors for the development of dementia after an intensive care unit (ICU) admission in a sample of older beneficiaries of Medicare. Older age was strongly associated with a diagnosis of dementia. The relationship between older age and development of dementia after critical illness has not previously been reported. After adjustment for known dementia risk factors, the multivariable analysis found that factors associated with the critical illness were associated with an increased risk of dementia. This study has several limitations - including use of ICD-9-CM codes that identified primarily neurodegenerative types of dementia, the lack of a control group, and a high mortality rate during the first 6 months after hospital discharge - which the authors acknowledge. An important additional limitation of the study by Guerra and colleagues and all previous post-ICU cognitive outcome studies is the inability to determine what role, if any, cognitive impairments that existed before the critical illness contribute to the diagnosis of new post-ICU dementia and whether such cognitive impairments are stable over time or are progressive like those observed in neurodegenerative diseases. Research is needed to answer questions regarding mechanisms of injury, medical and personal risk factors, and importantly the effect of interventions administered either during or after ICU treatment that may prevent or ameliorate such impairments.
\end{abstract}

*Correspondence: mona_hopkins@byu.edu

'Psychology Department and Neuroscience Center, 1022 SWKT, Brigham Young University, Provo, UT 84602, USA

Full list of author information is available at the end of the article
Large numbers of patients are treated in intensive care units (ICUs) each year in the US [1], and many individuals who survive a critical illness are left with significant physical and cognitive morbidities. Recent investigations indicate that post-critical illness cognitive impairments occur after the critical illness [2,3], affect multiple cognitive domains (that is, memory, attention, and executive function), are moderate to severe in nature [4], and persist months to years after hospital discharge [5]. In the previous issue of Critical Care, Guerra and colleagues [6] assessed risk factors for the development of dementia after an ICU admission in a sample of older beneficiaries of Medicare. The study, which randomly sampled $5 \%$ of Medicare beneficiaries who were treated in an ICU during 2005, used the International Classification of Diseases, 9th Revision, Clinical Modification (ICD-9-CM) codes to identify a new diagnosis of dementia during the first 3 years after the ICU hospitalization. The mean age of the survivors was 76.6 years, and dementia was diagnosed in $17.8 \%$ of patients, a rate that is higher than the incidence rate of dementia in older patients in the US [7]. Older age in this study was strongly associated with a diagnosis of dementia. After adjustment for known dementia risk factors (for example, age, prior cardiac surgery, or treatment in an intermediate ICU), the multivariable analysis found that factors associated with the critical illness, including sepsis, infection, acute neurologic dysfunction, and renal replacement therapy, were associated with an increased risk of dementia [6]. Thus, critical illness or factors associated with the illness increase the risk of developing dementia within 3 years of hospital discharge.

Guerra and colleagues [6] confirm recent findings that critical illness and sepsis are associated with the development of new cognitive impairments [2,3] and add important new information regarding the effect of aging and the contribution of factors associated with the critical illness in the development of dementia in these older individuals. The relationship between older age and development of post-critical illness cognitive outcomes has not been studied enough. Many patients admitted to ICUs are older, and over half of ICU admissions are for 
individuals over the age of 65 years [8]. While older age is a risk factor for cognitive decline and dementia in normal aging $[9,10]$, the interaction between aging and critical illness in the development of post-ICU cognitive impairment is unclear, as the mean age of survivors in most prior cognitive outcome studies after critical illness is approximately 54 years [11]. Guerra and colleagues [6] found that older age was strongly associated with a diagnosis of dementia, and in the oldest survivors (at least 85 years old), the cumulative incidence of dementia was $33 \%$. While this finding is not unexpected, the relationship between older age and development of dementia after critical illness has not previously been reported.

This study has several limitations, including the use of ICD-9-CM codes that identified primarily neurodegenerative types of dementia (senile, pre-senile, vascular, Alzheimer's disease, cerebral degeneration, and so on), lack of a control group, and a high mortality rate during the first 6 months after hospital discharge, all of which the authors acknowledge. An important additional limitation of the study by Guerra and colleagues [6] and all previous post-ICU cognitive outcome studies is the inability to determine what role, if any, cognitive impairments that existed before the critical illness play in the diagnosis of new post-ICU dementia. That is, it is unclear whether the diagnosis of dementia in this study represents (a) new post-ICU acquired cognitive impairment (for example, dementia), (b) new cognitive impairment plus age-related cognitive decline that became unmasked after the critical illness, (c) new cognitive impairment plus undiagnosed dementia that existed before the critical illness, (d) undiagnosed dementia that has no relationship to the critical illness, or (e) cognitive impairment due to other diseases such as cerebrovascular disease, which are common in older patients [12]. While it is impossible to separate the contributions of preexisting cognitive impairment from those of new cognitive impairment in the diagnosis of dementia in these older survivors of critical illness, this study found that factors associated with the critical illness (for example, sepsis, infection, acute neurologic dysfunction, and renal replacement therapy) were independently associated with a diagnosis of dementia [6]. It is also unclear whether the dementia identified by Guerra and colleagues [6] represents stable cognitive impairments (for example, impairments that do not progress over time) similar to the cognitive impairments that occur after traumatic brain injury, anoxic brain injury, or previously reported after critical illness $[4,5,13,14]$ or whether the dementia represents instead a progressive neurodegenerative dementia such as Alzheimer's disease. Research is needed to answer these and other important questions regarding the effect of critical illness on cognitive function, including mechanisms of injury, medical and personal risk factors, and importantly the effect of interventions either in the ICU or during post-ICU physical [15] and cognitive rehabilitation - that may prevent or ameliorate such impairments.

\section{Abbreviations}

ICD-9-CM, International Classification of Diseases, 9th Revision, Clinical Modification; ICU, intensive care unit.

\section{Competing interests}

The author declares that she has no competing interests.

\section{Author details}

1Psychology Department and Neuroscience Center, 1022 SWKT, Brigham Young University, Provo, UT 84602, USA. ²Department of Pulmonary and Critical Care Medicine, Intermountain Medical Center, 5121 S. Cottonwood Street, Murray, UT 84107, USA.

\section{Published: 6 February 2013}

\section{References}

1. Adhikari NK, Fowler RA, Bhagwanjee S, Rubenfeld GD: Critical care and the global burden of critical illness in adults. Lancet 2010, 376:1339-1346.

2. Iwashyna TJ, Ely EW, Smith DM, Langa KM: Long-term cognitive impairment and functional disability among survivors of severe sepsis. JAMA 2010, 304:1787-1794.

3. Ehlenbach WJ, Hough CL, Crane PK, Haneuse SJ, Carson SS, Curtis JR, Larson EB: Association between acute care and critical illness hospitalization and cognitive function in older adults. JAMA 2010, 303:763-770.

4. Hopkins RO, Jackson JC: Short- and long-term cognitive outcomes in intensive care unit survivors. Clin Chest Med 2009, 30:143-153.

5. Hopkins RO, Weaver LK, Collingridge D, Parkinson RB, Chan KJ, Orme JF Jr: Two-year cognitive, emotional, and quality-of-life outcomes in acute respiratory distress syndrome. Am J Respir Crit Care Med 2005, 171:340-347.

6. Guerra C, Linde-Zwirble WT, Wunsch H: Risk factors for dementia after critical illness in elderly Medicare beneficiaries. Crit Care 2012, 16:R233.

7. Plassman BL, Langa KM, Fisher GG, Heeringa SG, Weir DR, Ofstedal MB, Burke JR, Hurd MD, Potter GG, Rodgers WL, Steffens DC, McArdle JJ, Willis RJ, Wallace RB: Prevalence of cognitive impairment without dementia in the United States. Ann Intern Med 2008, 148:427-434

8. Milbrandt EB, Eldadah B, Nayfield S, Hadley E, Angus DC: Toward an integrated research agenda for critical illness in aging. Am J Respir Crit Care Med 2010, 182:995-1003.

9. Kukull WA, Higdon R, Bowen JD, McCormick WC, Teri L, Schellenberg GD, van Belle G, Jolley L, Larson EB: Dementia and Alzheimer's disease incidence: a prospective cohort study. Arch Neurol 2002, 59:1737-1746.

10. Rocca WA, Cha RH, Waring SC, Kokmen E: Incidence of dementia and Alzheimer's disease: a reanalysis of data from Rochester, Minnesota, 1975-1984. Am J Epidemiol 1998, 148:51-62.

11. Hopkins RO, Girard TD: Medical and economic implications of cognitive and psychiatric disability of survivorship. Semin Respir Crit Care Med 2012, 33:348-356.

12. Schneider JA, Arvanitakis Z, Bang W, Bennett DA: Mixed brain pathologies account for most dementia cases in community-dwelling older persons. Neurology 2007, 69:2197-2204.

13. Mikkelsen ME, Christie JD, Lanken PN, Biester RC, Thompson BT, Bellamy SL, Localio AR, Demissie E, Hopkins RO, Angus DC: The Adult Respiratory Distress Syndrome Cognitive Outcomes Study: long-term neuropsychological function in survivors of acute lung injury. Am J Respir Crit Care Med 2012, 185:1307-1315.

14. Girard TD, Jackson JC, Pandharipande PP, Pun BT, Thompson JL, Shintani AK, Gordon SM, Canonico AE, Dittus RS, Bernard GR, Ely EW: Delirium as a predictor of long-term cognitive impairment in survivors of critical illness. Crit Care Med 2010, 38:1513-1520.

15. Hopkins RO, Suchyta MR, Farrer TJ, Needham D: Improving post-intensive care unit neuropsychiatric outcomes: understanding cognitive effects of physical activity. Am J Respir Crit Care Med 2012, 186:1220-1228.

doi:10.1186/cc11913

Cite this article as: Hopkins RO: The brain after critical illness: effect of illness and aging on cognitive function. Critical Care 2013, 17:116. 